BRAIN. Broad Research in Artificial Intelligence and Neuroscience

ISSN: 2068-0473 | e-ISSN: 2067-3957

Covered in: Web of Science (WOS); PubMed.gov; IndexCopemicus; The Linguist List; Google Academic; Ulrichs; getCITED; Genamics JoumalSeek; J-Gate; SHERPA/RoMEO; Dayang Journal System; Public Knowledge Project; BIUM; NewJour; ArticleReach Direct; Link+; CSB; CiteSeerX; Socolar; KVK; WorldCat; CrossRef; Ideas RePeC; Econpapers; Socionet.

2022, Volume 13, Issue 1, pages: 213-217 | https://doi.org/10.18662/brain/13.1/278

\section{Adaptation in Affective Video Games during the Covid-19 Pandemic}

\section{Vlad Constantin BANDAC ${ }^{1}$, Cristina STEFANESCU ${ }^{2}$}

1 "Elisabeta Doamna" Psychiatriy Hospital; Galati, Romania.

${ }^{2}$ Dunarea de Jos University of Galati, Romania.
Abstract: Though national players area unit on the average 35-44 years recent, most diagnoses of on-line recreation Disorder occur in adolescents.

This data point may be a symptom of the usually neglected role of Adults within the diagnostic method, the questionable initial line in perceiving a tangle of web use and games in their kids.

Parents' negative attitudes towards games and family quarrels are shown to be predictors of gambling addiction among adolescents.

Keywords: First COVID-19, gaming addiction, psychological impact, coping mechanis.

How to cite: Bandac, V.C., \& Stefanescu, C (2022). Adaptation in Affective Video Games during the Covid-19 Pandemic. BRAIN. Broad Research in Artificial Intelligence and Neuroscience, 13(1), 213-217. https://doi.org/10.18662/brain/13.1/278 


\section{Introduction}

Player behavior takes precedence over different activities, as different activities area unit taken to the boundary.

Low management over behavior. Even once the negative consequences occur, this behavior continues or escalates (Casvean et al., 2021; Sandu \& Damian, 2018; Sandu \& Nistor, 2020, Terec-Vlad, 2020). A diagnosing so means a "persistent or recurrent" pattern of behavior of "sufficient severity" has emerged, consistent with the ICD (Luca et al., 2020).

Ends up in vital impairment in personal, family, social, academic or activity functioning. The impact is real and will embody sleep disorders, diet issues, physical inactivity (Baroiu et al., 2021; Grigoras \& Ciubara, 2021).

\section{Research Methodology}

This paper uses the medical literature to identify the evolution of adaptation in affective video games during COVID-19, to determine the beneficial effects and to reveal some recommandations for video gamers.

\section{Discussions}

Though the utilization of games might not perpetually be helpful, exer games (a new generation of video games additionally called exergaming or active video games) seem as an alternate, feasible, attractive, and safe thanks to exercise for many folks (Pandele et al., 2021; Radulescu et al., 2020). Exer games, a replacement generation of video games additionally called exergaming or active video games, area unit associated with the thought the thought massive body movements with engaging digital games (Nechvatal, 1999; Taylor, 2002; Tozour, 2002). Visual and sensory system stimuli area unit combined with differing kinds of apparatus that enable users to maneuver to play. Exercise games, like classic video games, may be contend in multiplayer mode, which may facilitate increase social interaction in a very home surroundings. Presently, there area unit many sorts of games, like people who simulate cardiopulmonary exercise (e.g., walking, running, and cycling), sports (e.g., basketball, bowling, tennis, Ping-Pong, baseball), swimming, Ping-Pong, volleyball, beach volleyball Compared to on-line games, exercise games appear additional advantageous as a result they induce helpful physiological and psychological changes that aren't sometimes found in typical video games. Exercise games area unit able to improve levels of physical activity, performance of daily activities, muscle strength in older 
adults, heart rate, bodily property balance, psychological feature perform in older adults and relieving anxiety disorders (Silistraru et al., 2021). Games area unit glorious in increasing motivation for exercise, and exercise plays a very important role in managing the harmful health effects of social isolation, like a decrease in physical activity and a rise in inactive behavior (Bakkes et al., 2008; Manovich, 2002; Millington, 2006; Nareyek, 2004).

\section{Research Results}

The findings of beneficial effects are:

- Improved sensitivity to visual distinction in fifty hours of video games, for a amount of 10-12 weeks

- Rising attention and application

- Action video games improve players' ability to quickly and expeditiously find the targeted stimulant in a district to district parts.

- Players are able to focus and watch moving objects, though there are several distractions close.

- Rising distributive attention

- Action video games stimulate players' concentration, attention, perception and memory, developing their ability to create fast choices and solve issues expeditiously and safely.

\section{Conclusions}

The recommendations are:

- Manage stress effectively - Regular exercise in stress management, deep respiration, yoga or meditation to scale back stress and raise your mood, having personal time, area and reflection.

- Get correct sleep - sleep hygiene by keeping a sleep diary with the period and time of sleep.

Must:

- Be chosen for an exact time to travel to bed

- Avoid hour games

- Make sure that electronic play devices aren't hold on within the room

- Check that the room is quiet and dim.

\section{References}

Bakkes, S. C. J., Spronck, P. H. M., \& van den Herik, H. J. (2008). Rapid adaption of video game AI (Extended version). In P. Hingston, \& L. Barone (Eds.), 
2008 IEEE Symposium on computational intelligence in games (CIG'08) (pp. 7986). IEEE Computational Intelligence Society.

Baroiu, L., Dumea, E., Năstase, F., Niculeț, E., Fotea, S., Ciubara, A. B., Stefanopol, I. A., Nechita, A., Anghel, L., \& Ciubara, A. (2021). Assessment of Depression in Patients with COVID-19. BRAIN. Broad Research in Artificial Intelligence and Neuroscience, 12(2), 254-264. https://doi.org/10.18662/brain/12.2/204

Căşvean, T. M. ., Hodorogea, V., \& Căşvean, I. E. . (2021). The experience created by the social and cultural context constructed by video games: A digitization of life and death. Journal for Social Media Inquiry, 3(1), 19-31. https://doi.org/10.18662/jsmi/3.1/14

Grigoras, M., \& Ciubara, A. (2021). Looking into Pandora's Box between "Everything" and "But" -Depression, Pain of Losses the Next Pandemic of Humanity?. BR AIN. Broad Research in Artificial Intelligence and Neuroscience, 12(2), 326-334. https://doi.org/10.18662/brain/12.2/210

Luca, L., Burlea, S. L., Chirosca, A.-C., Marin, I. M., Ciubara, A. B., \& Ciubara, A. (2020). The FOMO Syndrome and the Perception of Personal Needs in Contemporary Society. BRAIN. Broad Research in Artificial Intelligence and Neuroscience, 11(1Sup1), 38-46.

https://doi.org/10.18662/brain/11.1Sup1/27

Manovich, L. (2002). The Language of New Media. MIT Press.

Millington, I. (2006). Artificial Intelligence for Games. Morgan Kaufmann Publishers Inc.

Nareyek, A. (2004). Artificial intelligence in computer games: State of the art and future directions. ACM Quene, 1(10), 58-65.

https://queue.acm.org/detail.cfm?id=971593

Nechvatal, J. (1999). Immersive ideals / critical distances. a study of the affinity between artistic ideologies based in virtual reality and previous immersive idioms [Doctoral Dissertation, Centre for Advanced Inquiry in the Interactive Arts (CAiiA)]. University of Wales College.

Pandele, V. F., Tucmeanu, A., Antohi, M. E., \& Ciubara, A. (2021). The effect of using facebook on elderly people during COVID-19 Pandemic. Archiv Euromedica, 11(5), 69-71. https://doi.org/10.35630/2199$\underline{885 X / 2021 / 11 / 5.19}$

Rădulescu, I. D., Ciubara, A. B., Moraru, C., Burlea, S. L., \& Ciubară, A. (2020). Evaluating the Impact of Dissociation in Psychiatric Disorders. BRAIN. Broad Research in Artificial Intelligence and Neuroscience, 11(3Sup1), 163-174. https://doi.org/10.18662/brain/11.3Sup1/132

Sandu, A., \& Damian, S-I. (2018). Perceived quality of life and responsibility for own health condition. Micro-research. Archiv Euromedica, 8(2), 18-23. http://journal-archiveuromedica.eu/archiv- 
euromedica 02 2018/PAGES archiv euromedica 022018 maket 271 2_2018-18_23.pdf

Sandu, A., \& Nistor, P. (2020). The dynamic perspective versus the cognitivebehavioral perspective in counselling. Moldavian Journal for Education and Social Psychology, 4(2), 50-59. https://doi.org/10.18662/mjesp/4.2/22

Silistraru, I., Ciureanu, A. I., Ciubara, A., \& Olariu, O. (2021). Prevalence of burnout in medical students in Romania during COVID-19 pandemic restrictions (preliminary data). Archiv Euromedica, 11(5), 12-15. https://doi.org/10.35630/2199-885X/2021/11/5.3

Taylor, L. N. (2002). Video games: Perspective, point-of-view, and immersion, Master's thesis. Graduate Art School, University of Florida.

Terec-Vlad, L. (2020). Some approaches regarding the philosophy of technology. Logos Universality Mentality Education Novelty: Philosophy \& Humanistic Sciences, 8(2), 28-34. https://doi.org/10.18662/lumenphs/8.2/43

Tozour, P. (2002). The perils of AI scripting. In S. Rabin, \& C. River (Eds.), AI Game Programming Wisdom (pp. 541-547). Ed. Media, Inc. 